\title{
What a Child Ought to Know at the End of His School Geography Course
}

\section{William Charles Moore}

To cite this article: William Charles Moore (1906) What a Child Ought to Know at the End of His School Geography Course, Journal of Geography, 5:7, 320-325, DOI: 10.1080/00221340608986137

To link to this article: http://dx.doi.org/10.1080/00221340608986137

曲 Published online: 20 May 2008.

Submit your article to this journal $₫$

Џll Article views: 5

Q View related articles $\sqsubset$ 


\title{
WHAT A CHILD OUGHT TO KNOW AT THE END OF HIS SCHOOL GEOGRAPHY COURSE
}

\author{
By WILLIAM CHARLES MOORE \\ Instructor and Supervisor of Geography, State Normal School, Salem, Mass.
}

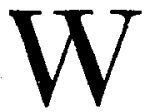

HAT a child ought to know at the end of his school course in geography concerns both the class-room teacher and the supervisor. The supervisor must have the ultimate aim of the course in mind, and, by a close articulation of the different grades, must make unity of work possible. He should also judge of the relative importance of different topics, so that the work as a whole shall be well balanced. But the actual results will depend in great measure upon the kind of work done by the class room teachers.

Different individuals will, of course, expect different results. In fact, there is much diversity of opinion among general superintendents of instruction as to what should be included within the course of study and in what order it should be taught. Notwithstanding these differences, however, a discussion of what may be expected at the end of the school course in geography ought to establish some common ground of greater or less extent.

One of the most fundamental results to be attained is an understanding of the relation of each individual to his surroundings. This is simply what is expressed, of course, in the usual definition of geography. All education is concerned in general in helping humanity adjust itself in relation to its mental and material environment. Geography not only contributes towards this end in a general way, but it also provides special. facilities for the interpretation of the conditions which determine the course and progress of the life of the times.

The basis for this interpretation must be derived by a systematic and progressive study of home geography. The lessons learned from the local features and conditions must not end with the fourth grade, however; to insure the results implied in this article, the geographical types of the home locality should be referred to in every grade. He is a good naturalist who knows his own parish, and a good juvenile geographer is one who has begun to realize how the local hills, valleys, plains, streams, coastal forms, and the prevailing conditions of temperature and moisture have influenced favorably or unfavorably the industrial, commercial, and social development of his own particular part of the world.

A recognition of the geographical bearing of current events brings 
the work of the schoolroom into a close, vital relation with the affairs of the outside world. From all parts of the globe the daily papers, the current magazines, and the monthly consular reports bring valuable geographical information. These items vitalize and make real the most important topics in geography. This custom of using current information, if practised in every grade, will help the pupil to realize that the text-book does not necessarily contain the latest or most authentic information. It teaches the pupil to use the atlas, the gazeteer and other sources and it helps to establish a habit which, in the years that follow school life, will tend to keep one's stock of geagraphical information up to date and available.

One of the most apparent aims in the study of geography is some knowledge of the principal physiographic types in their relation to life. Mountains, lofty and snow-capped, with steep irregular sides, attractive as scenic centers, and those worn down and subdued, useful in furnishing lumber, metals, coal, pasture, and possibly farming lands; valleys, steep sided and narrow, of doubtful value for settlements or for lines of travel, and others, broad and open, with slopes so gentle that, in affording both easy means of transportation and suitable sites for cities, they rival the plains of fluviatile, marine, or glacial origin; rivers in different stages of development, some providing natural facilities for moving merchandise and people and others furnishing valuable water power; coastlines that exhibit the principal features of the contact between the land and sea and-exemplify the advantages and disadvantages to man of varying degrees of irregularity, -all of these types, which are found throughout the world, are constantly recurring in the different grades and are a source of increasing geographical interest. A comparison of each new example of these different types with those already recognized in the previous grades serves as the very best kind of review. It helps to keep the names and locations of the principal mountain ranges, rivers, plains and coastal forms in mind. At the end of the school course, therefore, it may reasonably be expected that the pupil will have a fair degree of knowledge of the location and characteristics of the principal physiographic features of the world and a keen appreciation of the effect of these factors, individually and collectively, in determining the desirability of the earth for man.

A knowledge of the main facts about climate is another of the more important results to be expected. In every grade from the earliest to the latest, in the geography of the home locality and in the study of distant lands, the prevailing conditions of temperature and moisture are everpresent and important factors. The facts which constitute what is meant 
by climate are within the comprehension of every pupil; the explanation of these facts is another thing. To know that water passes into the air in an invisible form is a matter of simple observation and inference; so is the fact that this vapor when cooled sufficiently manifests itself as cloud, fog, dew, frost, rain or snow. A full explanation of the process by which this is brought about is too difficult for the grammar-school pupil, but a knowledge of the facts may reasonably be expected. The effect of latitude and of altitude upon temperature and the modifying influence of the proximity of large bodies of water are elements in the problem of climate which come within the range of the pupil's powers. That the wind is a movement of air caused by difference in atmospheric pressure, which, in turn, may depend upon variations in temperature, is a fundamental fact which leads to an understanding of the planetary circulation of the atmosphere, and finds many illustrations in the work of the different grades. Climate is without doubt one of the most complicated and difficult parts of geography; it is also the most important of the geographic controls. Man has overcome to some extent the limitations imposed by relief and by large bodies of water; but he can never hope, in the open, to defy climatic conditions. Throughout the study of this topic the training in the class-room ought to recognize the importance of making the understanding aid the memory in recalling such matters as the location of the principal heat belts, the circulation of the atmosphere and the distribution of rainfall.

The facts connected with the study of what is sometimes called astronomical geography ought to be well in mind at the end of the pupil's course in geography. By some educators the explanation of these facts is also attempted. The wisdom of including what is essentially astronomical will depend upon the time at the disposal of the teacher and the proficiency of the class. To introduce the explanation of the variation in the length of daylight and darkness and the change in the angle with which the sun's rays strike different portions of the earth at different seasons, in the fifth or sixth grades, or perhaps the seventh grade, as it is frequently done, is almost a waste of time. Facts themselves are matters of observation, pupils of all ages may be expected to see things; the explanation of what is observed, however, demands an exercise of the reasoning powers and this must wait for the development of the pupil's mind. The memorization of the teacher's explanation, expressed though it may be in words of the simplest character, does not necessarily imply understanding. The alternation of day and night is something within the experience of the most elementary pupil and its explanation involves simply turning a globe held in the sunlight. It is taken for granted, therefore, that the rotation of 
the earth upon its axis and the attendant consequences will be familiar facts. Other facts, which in themselves are matters of seasonal or even daily occurrence in the lives of the pupils, and which, therefore, everyone ought to know something about upon the completion of the course of study, are the diurnal paths of the sun at the time of the solstices and equinoxes as observed in the home latitude, the variations in the length of daylight and darkness, the diurnal and seasonal ranges of temperature for the locality in which the individual lives and the relation of temperature to length of day and inclination of the sun's rays.

These observations will lead naturally to the memorizing of other facts not within the pupil's own experience, like the position upon the earth's surface of the sun's vertical rays at different times of the year, the consequent location of the Tropics of Cancer and Capricorn, and the seasonal shifting of the heat equator and zones of heat.

The map and the globe are among the most important sources of geographical information. But the usefulness of the globe in showing, amony other things, the relative position and size of countries and continents is too seldom recognized, and the school-room map is usually poor. A greater number of facts and relations can be presented at once to the eye by a good map than could be gained by hours of study of lengthy verbal descriptions. To be able to read contour maps of large scale, like those of the U. S. G. S., to interpret the best wall maps intelligently, and to draw simple sketch maps of the continents ought to be among the most valuable results of a school course in geography.

The study of maps means something more than location. Most maps, however, with which pupils become familiar in their school course are not of much use for any other purpose. They show principally the outline of the continent, the boundaries of the political divisions, the location usually of too many cities and little more than the position of the mountains, rivers, lakes and coastal forms. The best maps show variation in altitude by different colors, or a scale of tones of the same color, intensity of relief by hachure lines and differences in the depth of the sea in tints of blue. Upon these maps the continents are presented with the third dimension, not in terms of plane figures. A map which does not show elevation, within a reasonable degree of accuracy, neglects to present an important factor of both relief and climate-the two most fundamental. things upon which the usefulness of the earth for the home of man depends.

The familiarity with the map which the pupil ought to carry away with him at the end of his school course is something different from an acquaintance with the names of the capes, bays, peninsulas, the boundaries 
or countries and State or the location of capitals and principal cities. Location, by the way, is best learned incidentally. For example, a familiarity with the position of the surface features in one's home locality is gained, not as the result of direct effort with the local map, but by frequently coming into relation with them in the every-day affairs of life. So, too, the location of distant places, is learned most effectively and naturally through the frequent associations and comparisons that form the basis of the best teaching. It is not a knowledge of location alone, therefore, which the pupil should possess but the ability to understand from a set of symbols the present or possible future relations of different portions of the earth to man. It is, in brief, the power to read from the map the physiographic and climatic conditions which affect the distribution of the world's population.

A knowledge of latitude and longitude is essential for the intelligent appreciation of any map. These terms ought by constant drill to mean something real and definite to the pupil so that when the formal school work is over the individual will use them easily and naturally. Too often, however, latitude and longitude are abstract things. This method of locating a place is made necessary by the spherical form of the earth. In no other way, in fact, can location upon the earth's surface be accurately determined. Expressing the position of a continent, country or city in terms of latitude and longitude ought to recall the relation of the map to the globe and the location of the place named in the world as a whole.

Throughout the work in geography the human element is a most important factor. The relation of relief and climate to man's occupration of the earth has already been dwelt upon. The life of the world depends not only upon the physical surroundings but also upon the characteristics of the people. One of the results of the school geography course, therefore, ought to be an acquaintance with the characteristics of the different races, states of society, forms of government and leading industries. In this study of the sociological conditions, as in the work with physical features, good examples of types are constantly occurring through the different grades. When the pupil reaches the last year in geography his previous training ought to have provided a good basis for the intelligent study and appreciation of the leading political institutions and the relation of a good government to industrial and commercial conditions.

To summarize: the results to be expected at the end of the course include principally a knowledge of those fundamental things which occur in some form or other in the legitimate work of nearly every grade. Consequently the more characteristic features, as a result of being approached 
from different points of view, at different times and in different ways, ought to become almost as familiar to the pupils as the multiplication table. The details of the work, which of course are indispensable for a lucid presentation of the main facts, will, it is expected, be forgotten. Indeed this is as it should be for then there is an opportunity for what is really important and characteristic to stand out in the memory. In general, it may be said that the study of geography in school ought to contribute towards developing the pupil's geographical sense or instinct. It ought to enable the individual to obtain the highest kind of satisfaction out of travel, and it ought to prepare the citizen in a measure to anticipate or predict the geographical possibilities and probabilities of different localities industrially, commercially and as dwelling places. Briefly, the things which have been suggested in the preceding paragraphs are the fundamental facts which form the basis of the geographical part of a good education.

\section{THE IMPROVEMENT OF SCHOOL GEOGRAPHY.}

Actual accomplished improvement in school geography can only be brought about by the teachers who perform the class-room work. It is more than gratifying therefore to find such interest in one of the most difficult subjects of the school curriculum that teachers make special efforts to study the subject and the teaching of the subject with a view to making their work more effective.

A Teachers Geography Club, organized several years ago in Boston, has done effective work among a small body of teachers. This year the club finds such interest in the subject that meetings will be held fortnightly. The Geographic Society of Chicago also reports widespread interest in geography among the teachers of that city and a club for the study of geography has recently been formed among the teachers of Buffalo.

All these signs of awakened interest indicate that, in spite of the progress of the last twelve years, teachers recognize that geography teaching is far from being what it ought to be and that improvement is being made so rapidly in the texts and courses of study that constant study is necessary to keep abreast of a subject, which, stagnant for a generation, has recently proved one of the most active subjects in the school curriculum. 